\title{
ANÁLISE DO COMPORTAMENTO DO ENXOFRE NO REFINO PRIMÁRIO DO AÇO*
}

\author{
Lucas Teixeira Costa \\ Roberto Parreiras Tavares ${ }^{2}$ \\ Nestor Cezar Heck ${ }^{3}$
}

\begin{abstract}
Resumo
A crescente demanda por aços ultrabaixo enxofre em usinas integradas a carvão mineral tem levado a esforços para reduzir o teor de enxofre no gusa e no aço. Todavia, a falta de uma visão integrada dos processos acarreta em otimizações isolados que nem sempre contribuem para uma efetiva redução de custos e aumento de produtividade final. No presente trabalho, foi construído e validado um balanço de massa capaz de realizar uma previsão do teor de enxofre de final de sopro a partir das entradas iniciais de enxofre na carga metálica e nas adições de fundentes. Para isso, considera-se que ocorre transferência de enxofre entre as fases, segundo seus teores e o coeficiente de partição de enxofre. A raspagem de escória de tratamento de gusa deve ser feita com muito cuidado para promover a melhor remoção da camada sobrenadante e ao mesmo tempo evitar perdas no rendimento metálico no processamento do aço. Utiliza-se o teor de enxofre do gusa carregado no LD como o principal parâmetro de controle, e recomenda-se que seu teor seja superior a 20ppm, uma vez que o esforço necessário para reduzir para teores abaixo desse limite será totalmente perdido no LD, devido à reversão durante o sopro.
\end{abstract}

Palavras-chave: LD; Reversão de Enxofre, Passagem de Escória, Balanço de Massa

\section{ANALYSIS OF THE SULPHUR BEHAVIOR IN PRIMARY STEELMAKING Abstract}

The increasing demand for ultra-low sulfur steel in integrated plants has led to efforts to reduce the sulfur content in the pig iron and steel. However, the lack of an integrated vision of processes leads to isolated optimizations that do not always contribute to effective cost reduction and ultimate productivity increase. In this paper, were developed and validated a mass balance capable of perform the prediction of the sulphur content at the end of BOF blow from the initial entries of sulphur in the metal load and the flux additions. It was considered that sulphur transfer occurs between the phases, according to its content and the sulphur partition coefficient. The handling and skiming of the slag must be done very carefully to promote better removal of the supernatant phase while avoiding metal losses in the steel processing. The sulphur of the pig iron loaded into LD is the main control parameter, and it is recommended that its content do not exceed 20ppm, since the effort to be reduced to levels below this limit will be totally lost in LD, due to the reversal during blowing

Keywords: BOF; Sulphur "pickup"; Slag carried; Mass Balance.

1 Bacharel em Química, Doutor em Metalurgia Extrativa, Solvi Insumos, Timóteo - MG, Brasil

2 Engenheiro Metalurgista, PhD, Professor Associado do Departamento de Metalurgia e Materiais da UFMG, Belo Horizonte - MG, Brasil.

3 Engenheiro Metalurgista, PhD, Professor Associado, Departamento de Metalurgia, UFRGS, Porto Alegre - RS, Brasil 


\section{INTRODUÇÃO}

O processo LD, também conhecido com o B.O.F (Basic Oxigen Furnace), é a etapa responsável por transformar o gusa em aço. Este processo se dá pela oxidação do silício e carbono presentes no metal pelo oxigênio injetado por lança em alta pressão e velocidade.

As cargas adicionadas no LD como o gusa líquido, os fundentes utilizados para o refino do aço, a sucata e a escória transferida do tratamento de dessulfuração do gusa para o LD são fontes consideráveis de enxofre.

A evolução do teor de enxofre ao longo do processamento do metal líquido no LD observado em experimentos industriais [1,2] é apresentada na figura 1.

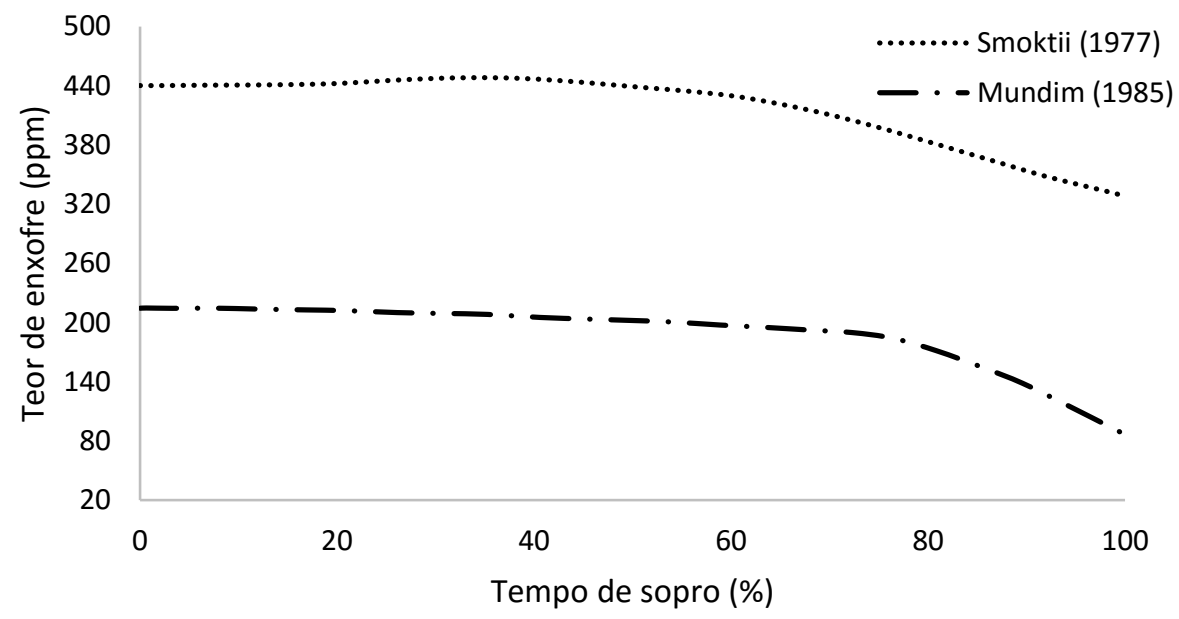

Figura 1 - Evolução do teor de enxofre durante o sopro no LD.

Embora não seja um reator especifico para a remoção de enxofre do metal, houve queda no teor de enxofre ao longo do tratamento LD de 210ppm para 90 ppm no tratamento realizado por Mundim (1985) e de 440ppm para 330ppm, no de Smoktii (1977). Deve-se ressaltar que os teores de enxofre de entrada estão em patamares elevados uma vez nos referidos trabalhos não foram realizados tratamentos de dessulfuração do gusa. Contudo, do ponto de vista do balanço de enxofre, pode-se afirmar que a quantidade de enxofre presente na escória e no metal no início do tratamento LD eram tais que o coeficiente de partição de enxofre favoreceu a dessulfuração.

O processo de dessulfuração no LD é termodinamicamente inviável devido ao elevado potencial de oxigênio. Portanto, o presente trabalho não se propõe a promover ou incentivar a prática de dessulfuração no refino primário do aço, pois há uma busca de integração do tratamento de forma a gerar benefícios produtivos e financeiros. Assim, a atuação no refino primário do aço indicada no presente trabalho, consiste basicamente em prever o teor de enxofre de final de sopro a partir do input de enxofre nas diversas adições de fundentes, gusa, sucata. De posse dessa previsão, há um campo para entender melhor as faixas de reversão do enxofre e atuar de forma a evitar ou amortece-las na etapa de refino primário.

A tabela 1 apresenta as faixas de teores de enxofre e oxigênio livre obtidos atualmente no final do sopro no convertedor LD [3]. 
Tabela 1 - Teores de elementos indesejáveis no final do tratamento LD

\begin{tabular}{cc}
\hline Elementos & Teores (\%) \\
\hline Enxofre & $0,008 \sim 0,012$ \\
Oxigênio livre & $0,060 \sim 0,120$ \\
\hline
\end{tabular}

Verifica-se que a faixa de teores de oxigênio livre obtidos no final de sopro é muito ampla e mesmo na faixa inferior são demasiadamente elevados e incompatíveis com a dessulfuração do aço.

A Figura 2 apresenta os teores de enxofre no início e fim de sopro de 81 tratamentos acompanhados no convertedor LD [4,5].

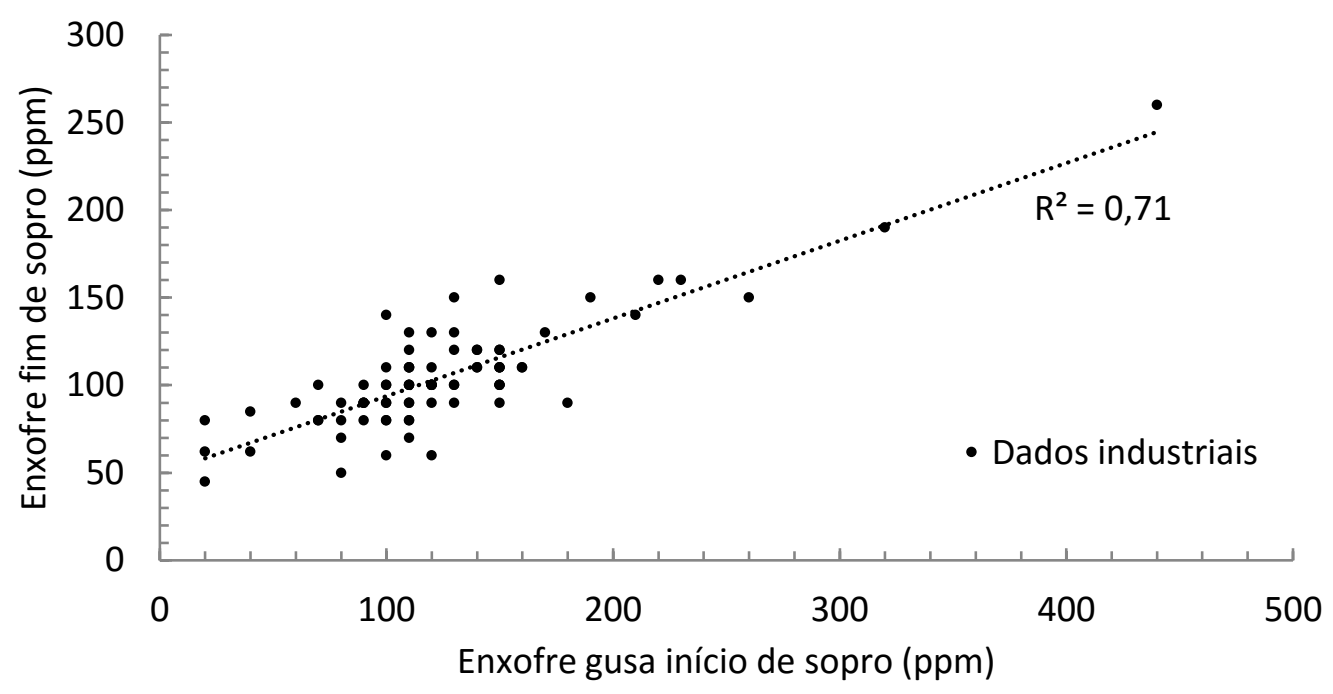

Figura 2 - Teores de enxofre no metal no início e fim de sopro

Nota-se claramente que existem outros fatores que afetam o teor de enxofre no fim de sopro. Isso se deve à grande dispersão dos teores de enxofre de final de sopro em relação a um determinado teor de enxofre inicial.

Por tudo isso, uma análise detalhada das influências de vários fatores será desenvolvida neste trabalho.

\section{MATERIAIS E MÉTODOS}

\section{1 - Partição de enxofre para escórias de convertedor LD}

A faixa de escória típica de LD é apresentada na tabela 2

Tabela 2 - Faixa típica de componentes da escória de convertedor LD

\begin{tabular}{cc}
\hline Componente & Faixa (\% em massa) \\
\hline Óxido de Cálcio $-\mathrm{CaO}$ & $23-46$ \\
Óxido de Magnésio $-\mathrm{MgO}$ & $5-13$ \\
Dióxido de Silício $-\mathrm{SiO}_{2}$ & $11-15$ \\
Óxido de Alumínio $-\mathrm{Al}_{2} \mathrm{O}_{3}$ & $0,8-2$ \\
Ferro total & $14-22$ \\
\hline
\end{tabular}


Utilizando o FactSage para a determinação da partição de enxofre de escórias de fim de sopro com composição química nas faixas apresentadas na tabela 2, obtevese valores calculados em $\mathrm{kg} / \mathrm{m} 3$ na faixa de 3,2 a 5,5 . No presente trabalho, foi utilizado o valor médio de 4,5.

Tais valores confirmam que o convertedor LD não é uma estação adequada para realização da dessulfuração. Mas que há um campo para melhor controle das corridas em que o baixo teor de enxofre é de grande importância.

\subsection{Balanço de Massa no convertedor LD}

Para o acompanhamento integrado da evolução de enxofre na cadeia produtiva do aço foi construído um balanço de massa para o convertedor LD, etapa que sucede o pre-tratamento de gusa. Portanto, entende-se que o comportamento do enxofre no convertedor LD é importante para se ter uma visão integrada do processo. Ainda que não seja uma etapa para dessulfuração, ela pode ocorrer em determinadas situações onde a entrada de enxofre no gusa seja mais elevada, superiores a 200 ppm.

Por meio de balanço de massa, foi avaliado o efeito da raspagem de escória que antecede o carregamento do LD e os teores de enxofre em todas as demais entradas no LD: gusa líquido, fundentes, sucata, escória passante. O balanço permitiu compreender melhor a magnitude da reversão de enxofre que é muito comum nessa etapa do processo, e também a compreensão de eventual dessulfuração.

Após terem sido consideradas todas as fontes de enxofre envolvidas no processo LD, uma rotina que leva em conta a concentração de enxofre no metal, na escória e a partição de enxofre no equilíbrio (Ls), foi desenvolvida para determinar o sentido de transferência de massa. A equação 1 representa a distribuição de enxofre entre as fases que é válida na condição de equilíbrio de transferência de enxofre no LD.

$$
C_{s \text { aço }}-\frac{C_{s e s c}}{L_{s}}=0
$$

$\boldsymbol{C}_{\boldsymbol{s} \text { fase }}=$ Concentração de enxofre em cada fase, $\mathrm{kg} / \mathrm{m}^{3}$;

$\boldsymbol{L}_{\boldsymbol{s}}=$ Partição de enxofre.

A partição de enxofre do sistema foi determinada por termodinâmica computacional utilizando o software comercial FactSage, no laboratório de siderurgia, LASID, na Universidade Federal do Rio Grande do Sul, UFRGS. Conhecida a partição de enxofre, a equação 1 pode ser resolvida e os teores iniciais de enxofre são distribuídos entre as fases para a condição de equilíbrio. O balanço de enxofre foi construído para os dados industriais disponibilizados por Carvalho (2012).

A Figura 3 apresenta o fluxograma da rotina de programação utilizada para calcular a dessulfuração ou reversão de enxofre no convertedor LD.

$$
L_{S}=\frac{\text { Conc. Escória }\left(\mathrm{kg} / \mathrm{m}^{3}\right)}{\operatorname{Conc.~Aço~}\left(\mathrm{kg} / \mathrm{m}^{3}\right)} \therefore C_{\text {Escória }\left(\mathrm{kg} / \mathrm{m}^{3}\right)}=C_{A c ̧ o\left(\mathrm{~kg} / \mathrm{m}^{3}\right)} * L_{S}
$$




\begin{tabular}{|c|c|c|c|}
\hline $\begin{array}{l}\text { Leitura de enxofre } \\
\left(\mathrm{kg} / \mathrm{m}^{3}\right) \text { no aço e } \\
\text { escória }\end{array}$ & $\begin{array}{c}\text { Teste: } \\
C_{\text {escória }}=C_{a \text { aco }} \cdot L_{s}\end{array}$ & $\stackrel{\mathrm{SIM}}{\longrightarrow}$ & $\begin{array}{l}\text { Atingido o fim } \\
\text { de tratamento }\end{array}$ \\
\hline 4 & $\downarrow N A \tilde{O}$ & & \\
\hline $\begin{array}{l}\text { Se: } \\
\text { Se: }\end{array}$ & $\begin{array}{l}C_{a c ̧ o} \cdot L_{s} \\
C_{a c ̧ o} \cdot L_{s}\end{array}$ & \multicolumn{2}{|c|}{$\begin{array}{l}\text { Dessulfuração, } S_{a c ̧ o} \rightarrow S_{\text {escória }} \\
\text { Reversão, } S_{\text {escória }} \rightarrow S_{a c ̧ o}\end{array}$} \\
\hline
\end{tabular}

Figura 3 - Fluxograma esquemático da rotina de previsão do enxofre no fim de sopro

Considera-se, que o enxofre transferido do metal para a escória ocorre com pequeno potencial químico de concentração (partição de enxofre baixa), ou seja, a escória de LD tem pouca eficiência em absorver o enxofre. Por isso, a possibilidade de reversão de enxofre ocorrer é grande e o teor total carregado no LD é fator importante no resultado final do sopro.

\subsection{Planejamento Experimental}

Um estudo da sensibilidade do teor de enxofre no fim de sopro em função das variáreis do processo foi realizado por meio de planejamento fatorial completo $2^{5}$ que resultou em 32 cálculos utilizando o balanço de massa proposto em cada experimento, utilizando os níveis apresentados na Tabela 4.

Tabela 4 - Níveis inferiores e superiores para teste de sensibilidade no LD

\begin{tabular}{ccccc}
\hline Escória passante (kg) & S Gusa (ppm) & S Cal (ppm) & S Sucata (ppm) & Fração Sucata $^{*}$ \\
$750-1500$ & $20-50$ & $600-1000$ & $50-150$ & $0,10-0,15$ \\
\hline *Peso de sucata / Peso de carga metálica & & &
\end{tabular}

O planejamento de experimentos gerou diferentes condições de entrada de enxofre no sistema para que a previsão de enxofre no final de sopro do LD pudesse ser feita com a menor margem de erro possível.

Os resultados foram submetidos a regressão linear a fim de obter uma expressão que represente corretamente a influência dos parâmetros estudados. Os principais efeitos e as melhores condições operacionais foram determinados.

\section{RESULTADOS E DISCUSSÃO}

São apresentados detalhadamente o funcionamento do balanço de enxofre realizado em duas condições iniciais de gusa tratado e não tratado, conforme na tabela 5.

Tabela 5 - Parâmetros de entrada no convertedor LD

\begin{tabular}{ccccc}
\hline Exemplo & Enxofre Gusa (ppm) & Enxofre escória (\%) & Peso gusa (t) & Escória Passante (kg) \\
\hline $\mathrm{a}$ & 20 & 1,54 & 315 & 1500 \\
$\mathrm{~b}$ & 400 & 0,57 & 315 & 500 \\
\hline
\end{tabular}

A figura 4 apresenta a evolução esquemática dos teores de enxofre no aço e na escória ao longo do tratamento até ser atingido o enxofre de equilíbrio entre as fases (partição de enxofre). 

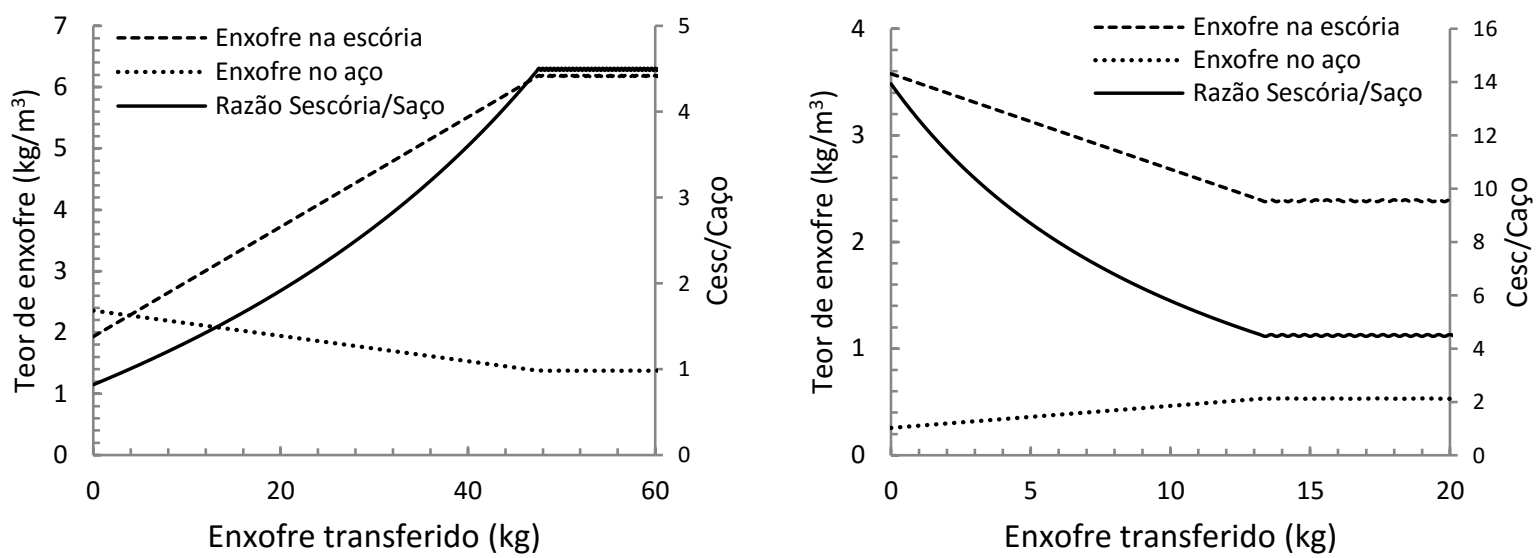

Figura 4 - Evolução esquemática dos teores de enxofre nas fases e a relação entre as concentrações (a) Enxofre inicial no gusa 20ppm (b) Enxofre inicial no gusa 400ppm.

Pode-se notar que ocorreu maior transferência de enxofre entre as fases no primeiro caso uma vez que o gusa carregado com 400ppm, havia muito mais enxofre no sistema que no caso do gusa carregado com baixo enxofre, 20ppm.

No carregamento do convertedor LD com gusa vindo do reator KR (exemplo a), temse uma escória de pre-tratamento de gusa muito concentrada, pois o tratamento de dessulfuração levou o teor de enxofre para 20ppm, conforme apresentado na Tabela 4. A escória, inicialmente muito concentrada, transferiu enxofre para o banho metálico que iniciou com 20ppm e termina o tratamento com teor de enxofre da ordem de 75ppm.

Para a condição de gusa não tratado (exemplo b), utilizou-se os valores típicos de teor de enxofre na escória de alto-forno. De posse dos dados indicados na tabela 4, a rotina de cálculo executa o balanço de massa até que a relação entre as concentrações de enxofre na escória e no metal atinja o valor de 4,5, partição de enxofre, a condição de equilíbrio do sistema é atingida e não há mais transferência de massa entre as fases. Pode-se dizer que ocorreu dessulfuração no convertedor LD.

O balanço de massa foi aplicado aos demais 30 experimentos do planejamento para diferentes condições de entrada de gusa, adição de sucata, e seus respectivos teores de enxofre.

Os teores de enxofre fim de sopro calculados pelo balanço de massa foram ajustados por regressão linear, permitiram obter a equação 2. Tal correlação permite prever o teor de enxofre de fim de sopro em função dos principais parâmetros de controle, já enumerados.

$S_{\text {fimLD }}=-1,54+0,363$ Sgusa $+0,0251$ Scal $+0,0587$ Ssuc $+48,3 f s u c+0,0215$ P. carread

A análise dos efeitos independentes de cada parâmetro operacional é apresentada na Figura 5, na qual se lê diretamente o efeito em ppm dos fatores investigados. 


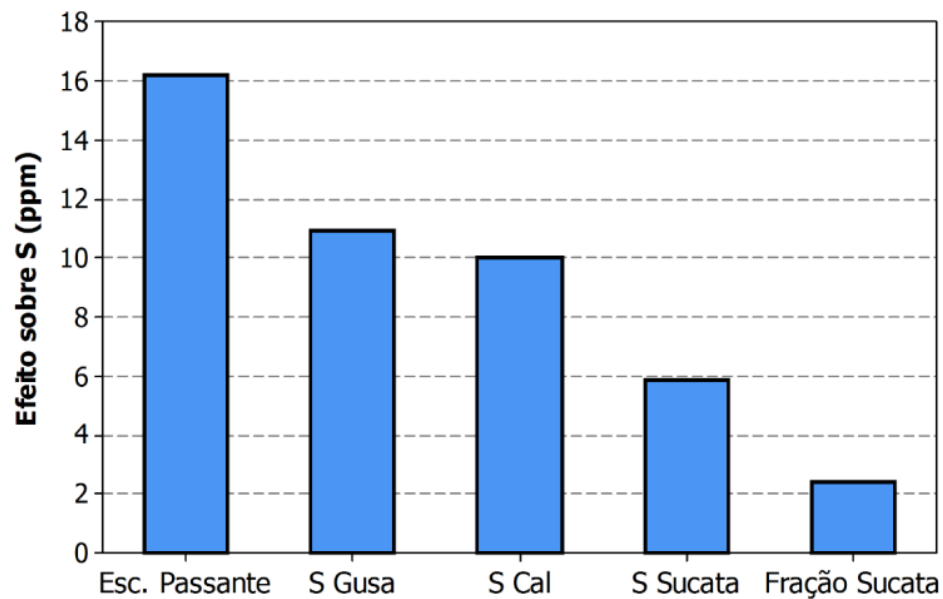

Figura 5 - Influência dos parâmetros de processo no "pick-up" de enxofre no LD.

O gráfico de barras dos efeitos mostra que o peso de escória passante apresenta maior influência no teor de enxofre no fim de sopro, 16ppm. Essa alteração é entendida da seguinte forma: o aumento gradual do peso de escória carregada no LD pode causar um aumento de até $16 \mathrm{ppm}$ no teor final do aço, partindo-se do menor valor de carregamento $(750 \mathrm{~kg})$ ao maior valor $(1500 \mathrm{~kg})$. Os demais parâmetros estão discriminados na referida figura por ordem decrescente de influência, e devem ser interpretados da mesma forma. A Figura 6 apresenta o tratamento com todos os efeitos testados em nível alto, em nível baixo e com a variação de cada um dos cinco efeitos listados na Tabela 4.

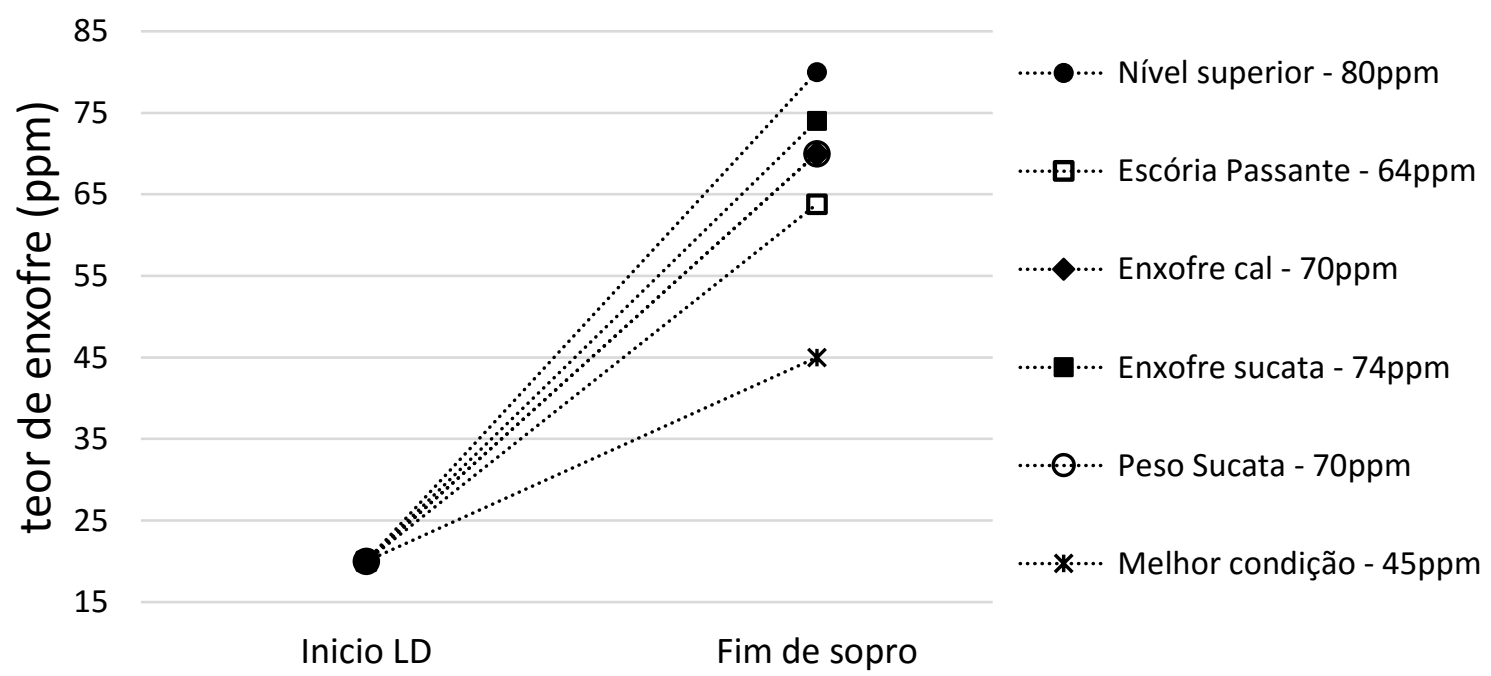

Figura 6 - Avaliação isolada dos parâmetros na reversão de enxofre no LD

Ainda sobre a passagem de escória na entrada do LD, tem-se um parâmetro de difícil controle pois, a raspagem de escória deve ser realizada de modo a evitar perdas metálicas. Isso implica em um remanescente de 500 a $1000 \mathrm{~kg}$ de escória passante. Portanto, existe um limite para o controle desse fator. A análise integrada pode indicar uma rota de produção que não dessulfure tão a fundo no pré tratamento de gusa, isso acarretaria em uma escória passante menos concentrada em enxofre, por exemplo. 
A figura 7 apresenta a reversão de enxofre durante o refino primário do aço no LD para duas condições de entrada com 20 e 50 ppm [6].

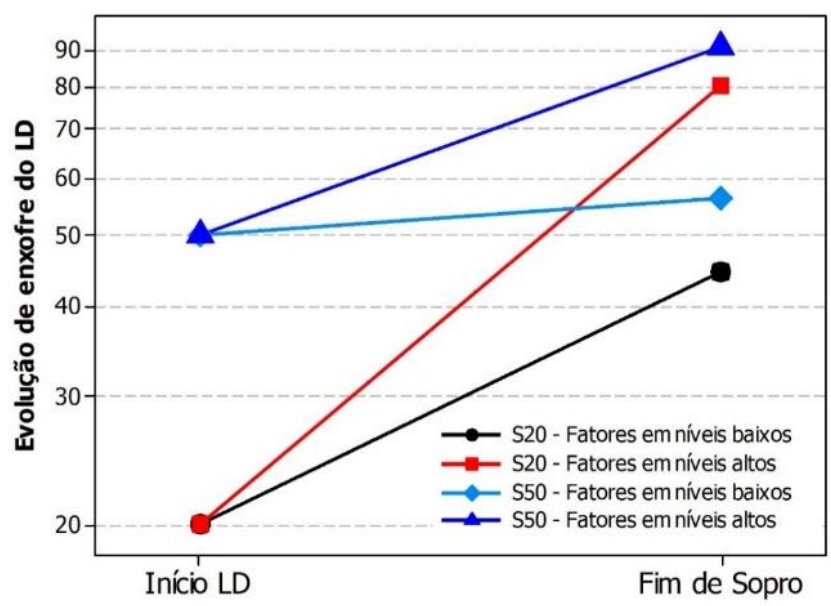

Figura 7 - Rotas com fatores em níveis altos e baixos para dois teores de enxofre na entrada do LD.

A figura permite observar o resultado da reversão dos teores de enxofre no fim de sopro, a partir de gusa dessulfurados para 20 e 50ppm, nas melhores e piores condições de controle de matéria prima. A prática a ser adotada em cada Usina deve ser criteriosamente avaliada, sempre tomando como referência de análise o teor de enxofre visado no aço.

Ainda que se conseguisse fazer um controle rigoroso da entrada de matéria prima no LD, partindo-se de gusa com 20ppm, ocorreria uma reversão de enxofre da ordem de 25ppm. Esse controle só seria economicamente justificado na fabricação de aços com requisitos de qualidade muito rigorosos nos quais o ganho de 35ppm de enxofre se justificaria.

Considerando a dificuldade no controle dos parâmetros envolvidos no LD em níveis baixos dos fatores utilizados, parte considerável do esforço empreendido na dessulfuração de gusa será desperdiçado em uma maior reversão no refino primário do aço. Em nenhum aço, mesmo os que apresentarem requisitos de qualidade mais rigorosos, se justifica dessulfurar o gusa para teores inferiores a 20ppm.

\section{CONCLUSÃO}

Foi desenvolvido e validado um balanço de enxofre no refino primário que permitiu identificar os fatores que afetam o teor final de enxofre no fim de sopro. Os fatores que mais afetam são, pela ordem decrescente, volume de escória carreado do tratamento do gusa para o LD, teor de enxofre inicial do gusa e teor de enxofre na cal.

A partição de enxofre em escórias típicas de fim de sopro no LD, determinada por meio do software FactSage, varia na faixa de 3,2 a 5,5, com valor médio de aproximadamente 4,5 .

A escória de tratamento de gusa transferida para o LD reponde por um incremento de enxofre de 16 ppm. Contudo, a raspagem deve ser feita com muito cuidado para que se atinja o limite de raspagem que ainda não descarta metal líquido, a fim de evitar perdas no rendimento metálico no processamento do aço. 
O teor de enxofre inicial do gusa, outro fator de grande importância no balanço de massa, deve ser estimado de acordo com o teor de enxofre objetivado no aço para evitar esforços desnecessários no tratamento de gusa. Não é recomendável que o teor de enxofre no gusa seja inferior a 20 ppm, uma vez que o enorme esforço necessário para reduzir além desse teor será totalmente perdido no LD, devido à reversão durante o sopro.

\section{Agradecimentos}

À FAPEMIG, pelo apoio financeiro concedido ao projeto Processo PPM-00118-13 Título: Modelagens física e matemática do escoamento multifásico em reatores metalúrgicos".

À CAPES/PROEX, pelo apoio ao programa de pós-graduação PPGEM/UFMG. Ao CNPq, pela bolsa de doutorado, processo 140893/2012-1.

\section{REFERÊNCIAS}

1 Mundim, M.J. Tecnologia de fabricação de aço líquido; UFMG, 3ª Edição, Volume 2,1985, 240P.

2 Smoktii VV, Lapitskii VV, Vyshivanyi AG, Teverovskaya AB, Vinnik N Yu, Lysenko NIL. An investigation of the process of bottom blowing with oxygen in a laboratory converter. Izvestia VUZ Chemaya Metalurgia, 1977, Cap.6, p42-45.

3 Barão C, Introdução à fabricação de aços no Processo LD. Curso Refino Primário de Aços, ABM, São Paulo, 2006

4 Carvalho F. Redução do Teor de Fósforo dos Aços em Convertedores LD Através de Adição de Briquete - Dissertação de Mestrado, CPGEM - UFMG, 2012

5 Dahlin A, Eriksson J, Tilliander, Jonsson PG, Influence of ladle slag additions on BOF process under production conditions, Ironmaking \& Steelmaking, 39:5, 318-326, 2012

6 Costa L, Tavares R, Heck N, Braga B, Passagli C, Análise Integrada dos Processos de Dessulfuração para Otimização de Rotas na Produção de Aço, 46 Seminário de Aciaria, ABMWEEK 2016. 